\title{
Bioethics and New Testament
}

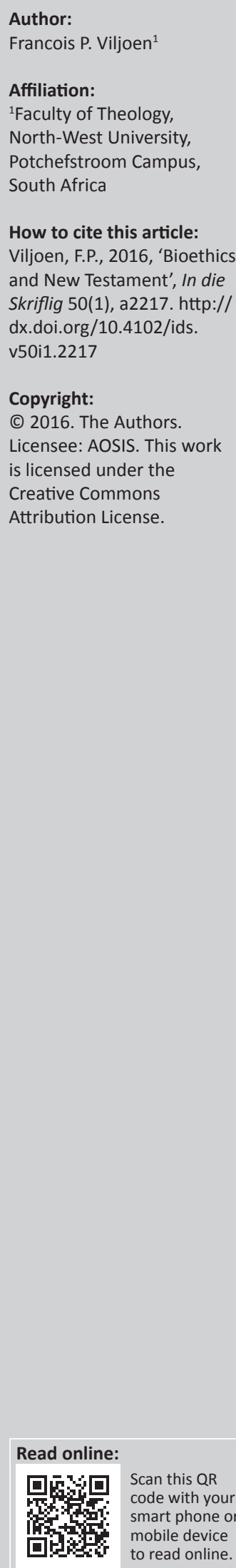

As a continuing endeavor to grow international scholarly ties and to stimulate discourse on current theological issues, interlinked mini-conferences were held respectively at the North-West University (24 August 2015) and the University of Stellenbosh (26 August 2015). Three well established scholars from three different continents were invited to each present a paper from different approaches to the topic of Bioethics and the New Testament, namely Prof J.M. Vorster from South-Africa, Prof R.A. Culpepper from the United States and Prof J-P. Wills from the Netherlands. The papers of these three scholars were circulated beforehand to designated scholars (Proff A.H. Verhoef, E. Mouton and Dr D.A. Forster respectively) who prepared academic responses to their papers during these mini-conferences. This publication contains these papers and responses as reworked into scholarly articles.

Prof J.M. Vorster's contribution is on the general revelation of God and creational gifts as a source for bioethics. His intention is to provide a Christian-ethical foundation for the development of moral codes for bio and eco-ethics. He concludes that natural knowledge, based on God's revelation as revealed by the natural sciences, provides Christian ethics with opportunities and means to formulate appropriate moral codes that can be applied in a secular society on condition that these ethical codes do not contradict the knowledge gained by God's revelation in Scripture. In such a way Christian ethics can positively contribute towards the development of bio and ecoethical concepts.

Prof A.H. Verhoef responds to Vorster with his article titled 'Sources of Bioethics: Lex Naturae vs. Sola Scriptura \& Sola Gratia?' While Verhoef acknowledges that it might seem as if the concept of natural law contradicts the reformational emphasis of sola scriptura and sola gratia, he agrees with Vorster that general revelation of God and creational gifts can be appropriate sources for bioethics, even within the reformed tradition. While identifying and analysing Vorster's arguments, Verhoef broadens the discussion by including an eschatological perspective, and the anthropology as proposed the Protestant philosopher, Paul Ricoeur.

Prof R.A. Culpepper contributes by offering a bibliological perspective to the topic. He develops the notion of Jesus as healer in the Gospel according to Matthew. His article is divided into two parts, to form two separate articles in this publication. In the first article he deals with methodological issues on Jesus as healer. He discusses the healing narratives in Matthew 8 and 9 by considering medical anthropological and social-scientific aspect of ancient Mediterranean culture. He demonstrates that 'healing' a person implied much more than the mere 'curing' of his/her disease. The goal was a total restoration of a person's well-being which includes social reintegration with families and communities. After setting the table with these methodological considerations, Culpepper proceeds by exploring the healing narratives in Matthew 8 and 9 . He concludes that a critically and culturally informed interpretation of Matthew's healing narratives may promote broader understanding of healing.

Prof E. Mouton responds to Culpepper. She focuses on three sets of implications of Culpepper's work, namely the implications of a bioethical reading of Matthew, the implications of a vulnerable, compassionate God in the midst of suffering, and implications of a comprehensive healing ministry for Christian churches today. She demonstrates how Jesus of Nazareth expresses God's presence amidst suffering. Jesus identifies with people in need while embodying God's renewal of fallen creation.

Prof J-P. Wills poses the question whether medical ethics do have a future. He raises concern for 'just healthcare' and 'just health' amidst the fast growing developments in biotechnology, pharmaceutics, and increased possibilities in lifestyles and life-extensions. He argues that the future medical ethics depends on a clear definition of good health and what 'just health' really means when viewed against the background of the social causes of health and disease. 
Dr D.A. Forster provides an appreciative contextual response to Wills' notion of 'just health', by approaching the notion of just health in the South African context from a public theological vantage point. He adopts a position that seeks to constructively engage empire, economics and apathy in relation to just health in South Africa.
We trust that these conferences and publication do stimulate scholarly consideration of bio-ethics from a biblical perspective and will contribute towards just health, while considering God's general revelation and natural gifts, but also appreciating the biblical perspective of God's compassionate and healing presence amidst a vulnerable fallen creation. 